\title{
ANÁLISE DA NOÇÃO DE TRABALHO DECENTE EM SEUS ASPECTOS CONCEITUAL, TERMINOLÓGICO E LEGAL
}

\section{ANALYSIS OF THE NOTION OF DECENT WORK IN ITS CONCEPTUAL, TERMINOLOGICAL AND LEGAL ASPECTS}

\author{
Vanessa Vieira Pessanha ${ }^{1}$
}

\section{RESUMO}

O presente artigo versa sobre a noção de trabalho decente, especialmente nas perspectivas conceitual, terminológica e legal, analisando seu alcance, sua relevância para a concretização da dignidade da pessoa humana e de que maneira o arcabouço legal existente contempla e estimula sua verificação prática. $\mathrm{O}$ objetivo reside em desenvolver uma apreciação mais detalhada da acepção criada pela Organização Internacional do Trabalho, compreendendo suas peculiaridades e procurando otimizar sua delimitação e aplicabilidade no mundo jurídico. A pesquisa é qualitativa, com método de revisão bibliográfica, elencando documentos diretamente relacionados (normas nacionais e internacionais) e consultando também outras fontes (sites oficiais e dicionários).

Palavras-Chave: Trabalho decente; Organização Internacional do Trabalho; Conceito; Terminologia; Conjunto normativo aplicável.

\begin{abstract}
The present article deals with the notion of decent work, especially in the conceptual, terminological and legal perspectives, analyzing its scope, its relevance for the realization of the dignity of the human person and how the legal set contemplates and stimulates its practical verification. The objective is to develop a more detailed appreciation of the meaning created by the International Labor Organization, understanding peculiarities and delimiting the application in the legal world. The research is qualitative, with method of bibliographical revision, listing directly related documents (national and international norms) and consulting other sources (official websites and dictionaries).
\end{abstract}

Keywords: Decent work; International Labor Organization; Concept; Terminology; Applicable normative set.

\footnotetext{
${ }^{1}$ Doutora e Mestre em Direito pela Universidade Federal da Bahia -UFBA, Bahia, (Brasil) . Especialista em Direito e Processo do Trabalho. Bacharela em Direito. Bacharela e Licenciada em Letras Vernáculas. Docente (UNEB). Pesquisadora. E-mail: vanessapessanha@ymail.com
} 


\section{INTRODUÇÃO}

A presente produção textual tem como escopo precípuo examinar a noção de trabalho decente nos aspectos conceitual, terminológico e legal, procurando registrar os limites adequados de acepção da expressão. Pelo reconhecimento de sua relevância prática, espera-se que essa estruturação mais detalhada de nuances do tema possa criar lastro para alavancar significativamente sua aplicabilidade, uma vez estando alicerçado em base mais sólida e conhecida.

Trata-se de uma pesquisa qualitativa, que tem como procedimento metodológico a revisão de bibliografia, além de normas brasileiras, instrumentos internacionais e outras fontes de pesquisa (como sites oficiais e dicionário).

Sendo o trabalho uma faceta de grande relevância da vida humana, não há como negar o imperativo de proteção do exercício dessa tarefa de maneira digna. Dignidade é uma abordagem basilar do artigo, não só por estar nominalmente mencionada no conceito de trabalho decente, mas principalmente por ser o grande fio condutor de toda a construção de salvaguarda dos trabalhadores em diversos aspectos, inclusive no que tange à noção de trabalho decente.

O conceito de trabalho decente foi criado pela Organização Internacional do Trabalho (OIT) e essa é a primeira abordagem do artigo, procurando enfrentar pontualmente todos os elementos que compõem a referida definição.

O estudo, além da análise jurídica, propõe também uma reflexão de natureza linguística. O segundo tópico principal de desenvolvimento do texto procura verificar a adequação da expressão trabalho decente no que diz respeito ao seu foco de atuação, sendo esse um dos fatores que atribui caráter multidisciplinar à pesquisa.

Por fim, o intuito consiste em demonstrar a plena harmonização que existe entre a noção de trabalho decente e os objetivos da OIT, bem como os diplomas legais (nacionais e internacionais) que podem ser utilizados como respaldo para a interpretação e aplicação do trabalho decente em território nacional. 
Tendo em vista a relevância dos conceitos para a compreensão e delimitação do campo de atuação dos institutos jurídicos, inicialmente a busca será pelo entendimento da abrangência adequada da noção ora em exame.

\section{A DEFINIÇÃO DE TRABALHO DECENTE E SEU ALCANCE}

A acepção oficial de trabalho decente foi cunhada pela Organização Internacional do Trabalho (OIT) em 1999: "entende-se por trabalho decente um trabalho adequadamente remunerado, exercido em condições de liberdade, equidade e segurança, capaz de garantir uma vida digna" (OIT, 2010).

No que diz respeito especificamente ao conceito de trabalho decente proposto pelo referido organismo internacional, algumas expressões fundantes merecem destaque: trabalho adequadamente remunerado, liberdade, equidade, segurança e vida digna.

$\mathrm{O}$ primeiro componente, trabalho adequadamente remunerado, corresponde à meta das relações de trabalho - em oposição à atividade em sentido estrito, como explica Luciano Martinez (2016, p. 125). Vale registrar também que, em se tratando de relação de emprego espécie do gênero relação de trabalho -, a onerosidade figura como um dos elementos essenciais à sua caracterização (SUSSEKIND et. al, 2005 - dentre muitas opções de obras juslaboralistas).

Aspecto que merece destaque de pronto é o fato de esse tema ser objeto de preocupação por parte da OIT há muitos anos, podendo ser citado o exemplo da Convenção $\mathrm{n}^{\circ}$ 26, que entrou em vigor no cenário internacional a partir de 1930, tratando justamente de métodos de fixação de salários mínimos, isto é, para a aferição de valores apropriados de pagamento aos trabalhadores.

Não se trata, destarte, de uma mera remuneração, ou seja, de qualquer pagamento pelo serviço prestado. A menção é a uma remuneração adequada (um dos principais direitos econômicos - direito humano de segunda dimensão -, segundo BRITO FILHO, 2013, p. 52), expressão que encerra grande valor simbólico, porém difícil mensuração prática. Não se deve perder de vista, por exemplo, que toda mão de obra assalariada não ganha o que efetivamente seria o valor do que produz; dessa forma, recebe levando em conta a ideia de mais valia, como ensinam Marx e Engels (2014). Além disso, em alguns tipos de trabalho, essa aferição torna- 
se ainda mais difícil, como no caso das pessoas que exercem labor com produção de arte ou bens imateriais de outros tipos, pois o próprio ato de atribuir preço às produções, apesar da tentativa de levar em consideração elementos objetivos (exemplos: projeção do autor, alcance da obra, finalidade prática ou contemplativa, erudição ou simplicidade etc.), possui um grau significativo de subjetividade.

Um parâmetro relevante acerca dessa questão é a própria noção de salário mínimo, sendo concebida, em linhas gerais, como o limite mais baixo de remuneração que um trabalhador deve receber pelo serviço prestado. Vale registrar que, apesar de haver exceção à regra de pagamento do salário mínimo como menor parâmetro contraprestativo (como dispõe a orientação jurisprudencial $n^{\circ} 358$ da SDI-1 do Tribunal Superior do Trabalho - TST), esse é um elemento importante no cotidiano da classe trabalhadora, haja vista a existência de um contingente significativo de pessoas chamadas assalariadas (assim entendidos aqueles que recebem como remuneração o salário mínimo). Registre-se, contudo, que o salário mínimo, nos moldes atuais, não consegue atender todos os pontos listados no art. $7^{\circ}$, IV da Constituição Federal de 1988 (CF/88), dentre os quais moradia, alimentação, educação, saúde, lazer e higiene.

Nas palavras de Amauri Mascaro Nascimento (2008, p. 164):

O salário mínimo atende a um imperativo de tutela das classes de baixa renda e qualificação profissional, como forma de intervenção do Estado ou da autonomia privada coletiva destinada a impedir que os níveis socioeconômicos inferiores da escala de remuneração possam ser protegidos através de uma regra jurídica proibitiva.

Não se deve perder de vista também a dimensão socioeconômica do salário, uma vez que, para além da retribuição pelo serviço prestado e da condição de resultado de relações econômicas, o salário é considerado verba de natureza alimentar, tendo em conta a destinação clássica à subsistência do trabalhador - e, muitas vezes, também a de sua família (NASCIMENTO, 1997, p. 33-35).

Assim, parece razoável entender que remuneração adequada pelo trabalho prestado, fazendo uma interpretação sistêmica do próprio conceito de trabalho decente e das questões de ordem social, corresponde a uma remuneração que não seja aviltante, que permita ao trabalhador ter acesso (e dar acesso à sua família, se for o caso) ao menos aos bens considerados de primeira necessidade, atribuindo-lhe(s), portanto, uma vida digna.

O segundo componente - liberdade - trata-se de um dos bens considerados mais caros para o ser humano. O conceito de liberdade de Jean Rivero e Hugues Moutouh (2006, p. 8) é 
elucidativo: "a liberdade é um poder de autodeterminação, em virtude do qual o próprio homem escolhe seus comportamentos pessoais".

Assim, a noção de liberdade caminha no sentido de manutenção da essência do indivíduo no exercício de uma das facetas de sua vida, qual seja, a atividade laboral, devidamente adaptada para a conjuntura específica ora em estudo.

Ponderando a palavra, podem ser pensadas algumas vertentes de interpretação, como a liberdade de exercício da profissão (a título de exemplo, uma possível leitura dessa vertente é a de SILVA NETO, 2009, p. 99-119), a liberdade material de escolha na determinação do caminho profissional que o indivíduo deseja seguir (nesse sentido, PESSANHA, 2015, passim) e a não sujeição do indivíduo ao exercício não espontâneo do trabalho (afastando, por exemplo, o trabalho forçado). No contexto do conceito de trabalho decente, costuma ganhar maior notoriedade a terceira possibilidade, uma vez que é um tema atrelado às discussões que envolvem trabalho em condição análoga à de escravo.

Para aclarar a diferença entre trabalho em condição análoga à de escravo e trabalho forçado, Manoel Jorge e Silva Neto (2013, p. 464) elucida: “o trabalho forçado não deve ser confundido com o trabalho escravo, pois este é o conteúdo do qual aquele é o continente".

O terceiro componente - equidade - também diz respeito a noções valiosas para a humanidade, tais como justiça, igualdade e honestidade.

Por esse aspecto, o trabalho em condições de equidade remete à aplicação da justiça no caso concreto - inclusive no que tange aos procedimentos de correção de desigualdade salarial (equiparação salarial, equivalência salarial, determinação supletiva do salário e enquadramento salarial), com o objetivo de efetivar o direito à isonomia salarial nos casos cabíveis -, a um tratamento ao trabalhador que passe por esse desígnio e, sobretudo, pela igualdade no sentido de não discriminação (LIMA, 2011).

Vale mencionar que essa abordagem, tendo em vista sua extrema importância na prática das relações laborais, consiste em uma das áreas de atuação do Ministério Público do Trabalho (MPT), operando na promoção da igualdade por intermédio de ações de combate aos mais diversos tipos de discriminação.

O quarto componente - segurança - faz referência a uma das questões que revelam o caráter de conquistas históricas do Direito do Trabalho: as normas que envolvem saúde, segurança, medicina e higiene do trabalho. 
Trabalhar em condições de segurança significa dizer que o ser humano, na prestação de serviço, tem o direito de serem observados os padrões e normas de segurança do trabalho, implantados como medida de proteção à saúde, à incolumidade física e psíquica, bem como à própria vida do trabalhador.

Faz-se mister mencionar que, dentre as muitas questões que envolvem o assunto ora abordado, ganha relevo a temática do acidente de trabalho. Como explica Sebastião Geraldo de Oliveira (2016) centrando-se na realidade do país, apesar das normas que disciplinam o assunto, os números no Brasil ainda não muito altos (cerca de dois mil acidentes dessa natureza por mês - devendo ser levada em consideração a subnotificação, prática de não se promover a publicização da ocorrência, como determinam as normas). Há uma necessidade de mudança de cultura, passando da monetarização dos riscos aos quais o trabalhador é submetido (MACHADO, 2001, p. 102-106) à concretização do direito a prestar labor em um ambiente de trabalho saudável.

Desses dados, percebe-se a relevância da atuação no sentido de fazer valer, na prática, o trabalho em condições de segurança de que trata o conceito em comento, demonstrando, em mais esse aspecto, a quantidade e, sobretudo, a profundidade de escopos dispostos na ideia de trabalho decente.

O quinto e último componente - vida digna - reflete o resultado que se espera do cumprimento de todos os demais componentes, bem como a própria razão de ser do enunciado proposto pela OIT.

Flávia Piovesan (2012, p. 86) demonstra a relevância do princípio da dignidade humana em sede nacional e internacional:

Sustenta-se que é no princípio da dignidade humana que a ordem jurídica encontra o próprio sentido, sendo seu ponto de partida e seu ponto de chegada, para a hermenêutica constitucional contemporânea. Consagra-se, assim, a dignidade humana como verdadeiro superprincípio, a orientar tanto o Direito Internacional como o Direito interno.

A dignidade, mencionada desde o primeiro artigo da $\mathrm{CF} / 88$ como um dos fundamentos da República Federativa do Brasil (art. $1^{\circ}$, III da CF/88) e uma das acepções mais relembradas em diversos contextos e áreas, consiste, sem dúvida, em elemento indispensável também à observância da dimensão principal de amparo do conceito de trabalho decente.

Pontue-se, por oportuno, que há a defesa patronal pelo acréscimo da ideia de produtividade ao conceito de trabalho decente, na medida em que auxilia na construção de uma acepção sustentável e fincada na realidade do mundo do trabalho, indicando também a 
competitividade econômica e o bem estar do trabalhador nesse contexto e, sobretudo, tendo em vista a indissolubilidade entre trabalho decente e empresa sustentável (CONFEDERAÇÃO DOS EMPREGADORES, 2011, p. 11; 13-15).

A título de informação, vale registrar que, apesar da implantação inicial dos direitos de primeira dimensão nos ordenamentos dos países, em âmbito internacional a primeira instituição internacional especializada em direitos humanos foi a Organização Internacional do Trabalho (OIT), cujo texto de começo pode ser encontrado na parte XIII do Tratado de Paz de Versalles de 1919 (OLVERA, 1998, p. 22).

O panorama geral do processo de implantação da OIT no cenário internacional é apresentado por Flávia Piovesan (2012, p. 179):

Criada após a Primeira Guerra Mundial, a Organização Internacional do Trabalho tinha por finalidade promover padrões internacionais de condições de trabalho e bem-estar. Sessenta anos após a sua criação, a Organização já contava com mais de uma centena de Convenções internacionais promulgadas, às quais Estados-partes passavam a aderir, comprometendo-se a assegurar um padrão justo e digno nas condições de trabalho.

Nota-se, a partir das informações citadas, que o conceito de trabalho decente representa a materialização de questões pelas quais a instituição já vem buscando lutar desde a sua criação e que, apesar do transcurso do tempo, ainda permanecem como pauta das mais importantes a ser implementada em todo o planeta.

\section{REFLEXÃO SOBRE A TERMINOLOGIA ADOTADA NO BRASIL}

Uma vez abordado o conceito de trabalho decente, seu alcance e algumas considerações necessárias sobre a OIT, julga-se pertinente, nesse momento, refletir sobre a expressão em comento.

Uma das questões que já se põe como de relevância quando o tema é pensado diz respeito à nomenclatura escolhida para uso no Brasil: trabalho decente (OIT, 2010a).

$\mathrm{O}$ adjetivo que acompanha o substantivo trabalho, na tradução para o português do Brasil, é a palavra decente. De acordo com o Dicionário Michaelis (2009), decente significa "1. Conforme com a decência; conforme as condições do bom viver, da boa sociedade; conveniente, decoroso, honesto. 2. Adequado, próprio. 3. Asseado, limpo”. No Dicionário Priberam (2013), “1. Conforme a decência. 2. Limpo, asseado. 3. Conveniente, próprio. 4. 
Honesto, decoroso". Há, portanto, registros bastante similares nos dois conjuntos de unidades lexicais.

Dentre os traços semânticos encontrados, percebe-se fortemente uma ligação com o aspecto moral, registrado, além de no próprio vocábulo pesquisado, em palavras como decência, condições da boa sociedade, conveniente, decoroso, honesto (que fazem parte das acepções ofertadas pelas duas fontes de pesquisa).

Quando confrontado com o conceito da OIT, o caminho de significado parece seguir em outra direção. Ou seja, o significante aponta para traços de indicação de moralidade, ao passo que a noção em si parece indicar sentido diverso.

Partindo da tradução brasileira, caberia o questionamento: o que se entende por trabalho decente? Aquele moralmente adequado? Que segue os parâmetros de valores e comportamentos sociais desejados dentro do conjunto de bons costumes esperados pela comunidade?

A julgar pelos estudos que vêm sendo desenvolvidos na área ${ }^{2}$ e a partir da leitura e das digressões já apresentadas até o momento, não parece ser esse o objetivo da estrutura proposta.

A expressão, em língua inglesa, é decent work (como se observa no site da Internacional Labor Organization), então a tradução literal mais objetiva - sem levar em consideração elementos valiosos para esse processo, tais como os aspectos culturais do país de destino da tradução desenvolvida - seria, de fato, trabalho decente. Barbosa (2007) posiciona-se sobre o assunto tradução e algumas indicações de mérito, valendo pontuar o quão importante é o cuidado na escolha do critério para sua realização.

Tendo em vista a relevância do elemento cultural para a compreensão do tema, Clifford Geertz (2012, p. 36) lembra:

Nossas ideias, nossos valores, nossos atos, até mesmo nossas emoções são, como nosso próprio sistema nervoso, produtos culturais - na verdade, produtos manufaturados a partir de tendências, capacidades e disposições com as quais nascemos, e, não obstante, manufaturados.

\footnotetext{
${ }^{2}$ Até porque, conforme mencionado no item anterior (2), o conceito de trabalho decente está atrelado à ideia de liberdade, que, por sua vez, remonta à liberdade de exercício da profissão, fato que pode ser relacionado a atividades que são lícitas, porém moralmente discriminadas na sociedade, a exemplo da prostituição. Nesse ponto, caberia um novo questionamento: seria esse um trabalho indecente? A questão do termo decente e sua carga semântica dizem muito do direcionamento que se pode atribuir a essa pergunta.
} 
A cultura é, sem dúvida, um elemento que pode influenciar uma série de entendimentos, dentre os quais é passível de enquadramento a noção de trabalho decente, uma vez que está intimamente ligada a valores.

Vale registrar - para ficar adstrito às principais línguas românicas - que, em espanhol, a tradução utilizada é trabajo decente; em francês, travail décent; e, em italiano, lavoro dignitoso. Todas foram devidamente encontradas nos sites oficiais da OIT nos respectivos países berços das línguas escolhidas (vide lista de referências), que as têm, portanto, como língua oficial e, por via de consequência, parte de sua identidade cultural.

É, porém, a expressão utilizada em Portugal que mais chama a atenção, sobretudo por ser, oficialmente, a mesma língua do Brasil: trabalho digno (OIT, 2010b).

Para além das discussões que envolvem o tema da língua portuguesa na perspectiva interna do Brasil (SILVA, 2004), a título de informação, vale registrar que há também o debate, em função do afastamento do português europeu e do português brasileiro, acerca da já possível ou não indicação de existência de duas línguas diferentes (MATEUS, 2006. p. 6380).

Percebe-se, portanto, que, apesar de mais óbvia em termos de signo linguístico, a expressão trabalho decente não seria a única possível, inclusive se partindo do pressuposto que, também em língua portuguesa (mas em território português), é adotada outra terminologia.

Não se deseja, aqui, criticar a prática de tradução literal, uma vez que consiste em uma das formas possíveis de apresentação das ideias, com seus méritos (a exemplo de tentar a fidedignidade das informações), porém não é a única. Cabe a leitura de AUBERT (1991, p. 185-192) nesse sentido.

Os indicadores registrados no conceito da OIT (trabalho adequadamente remunerado, liberdade, equidade, segurança e vida digna), devidamente pontuados no item anterior (2), tendem a recomendar a interpretação muito mais para a visão da dignidade do que para a moralidade.

Nesse sentido, apesar da adoção oficial no Brasil da expressão trabalho decente, vale o registro de que a terminologia trabalho digno carrega consigo a nomeação que mais parece se assemelhar às finalidades propostas pela OIT.

Em que pese a possibilidade de leituras diferenciadas desse conceito a partir do substrato cultural no qual esteja inserido, vale lembrar que existe um conteúdo de 
direcionamento proposto pela OIT, justamente buscando evitar a relativização de elementos fundamentais dessa ideia tão relevante.

Vencida a etapa de análise linguística e elementos circundantes desta, promovida com o desígnio de melhoria da compreensão do tema - e, como via de consequência relevante, de aplicação prática -, a abordagem será voltada, agora, para a busca dos registros de lei que atribuem suporte de aplicação da ideia de trabalho decente em âmbito mundial e no sistema jurídico brasileiro, antecedida da verificação de unidade entre os objetivos da OIT e tal ideia.

\section{TRABALHO DECENTE: HARMONIZAÇÃO COM OS OBJETIVOS DA OIT E ASPECTO LEGAL}

Analisado o conceito de trabalho decente e alguns elementos legais que dão sustentáculo a sua aplicação, o presente artigo almeja demonstrar a harmonia nítida com a Bse de existência da OIT, bem como apresentar alguns caminhos de conformação, tendo em vista a necessidade social de visualização prática do tema em exame.

\subsection{OS OBJETIVOS DA OIT E A IDEIA DE TRABALHO DECENTE}

O trabalho decente é considerado tão importante dentro da OIT justamente por sintetizar a missão histórica do organismo internacional e por ser considerado o ponto de convergência entre os quatro objetivos estratégicos da instituição:

[...] o respeito aos direitos no trabalho (em especial aqueles definidos como fundamentais pela Declaração Relativa aos Direitos e Princípios Fundamentais no Trabalho e seu seguimento adotada em 1998): (i) liberdade sindical e reconhecimento efetivo do direito de negociação coletiva; (ii) eliminação de todas as formas de trabalho forçado; (iii) abolição efetiva do trabalho infantil; (iv) eliminação de todas as formas de discriminação em matéria de emprego e ocupação), a promoção do emprego produtivo e de qualidade, a extensão da proteção social e o fortalecimento do diálogo social" (OIT, [ca. 2010]).

Os objetivos da OIT são calcados em elementos de grande valor social (a exemplo da eliminação de discriminação em matéria de emprego e ocupação), mesclados com a atuação da sociedade (fortalecimento do diálogo social), como forma de fazer valer na prática as 
metas relevantes que são propostas - porém, em muitos casos, ainda longe de serem efetivadas (como a eliminação do trabalho forçado, dentre outras questões).

Dessa forma, percebe-se que o conceito de trabalho decente consiste, em verdade, na interseção entre os caminhos que a OIT busca estabelecer como adequados quando se trata de trabalho humano. Ou seja, é como se, ao tratar de trabalho decente, a instituição conseguisse reunir, de maneira mais objetiva (mas nem por isso mais fácil), as diretrizes principais que entende ser as que precisam de concretização no mundo do trabalho.

Sobre a proteção social, vale registrar o entendimento da OIT (2012, p. 6):

As políticas de proteção social compreendem a garantia de condições de trabalho decente, como o respeito à legislação trabalhista e aos princípios de saúde e segurança no trabalho, bem como regimes de seguridade social e um conjunto de políticas para proteger grupos especialmente vulneráveis da população trabalhadora. Um sistema de proteção social efetivo contribui para um crescimento equitativo, a estabilidade social e a melhoria da produtividade.

Observa-se, a partir dessa digressão, que a proteção social almejada pela OIT, além da questão centrada no trabalhador em si, passa também pela visão do aspecto macro, inserindo inclusive a melhoria da produtividade como mecanismo de manutenção do sistema e, em última análise, a garantia da existência do próprio trabalho.

A respeito do diálogo social, a OIT (2012, p. 7) assevera que "o diálogo social tripartite entre governos, organizações de empregadores e de trabalhadores é o método por excelência de funcionamento da OIT [...]", entendendo que o fortalecimento desse diálogo corresponde a atividade de grande relevância, tendo em vista “" [...] o tratamento dos problemas e desafios do mundo do trabalho". O escopo da OIT consiste, portanto, no fomento ao diálogo, agindo de maneira a apoiar as "[...] principais organizações de trabalhadores e de empregadores de cada país, e no âmbito regional e internacional, via atividades de formação e assistência técnica nas diversas áreas compreendidas no seu mandato".

Compreendendo que concretizar o trabalho decente demanda empenho para além da simples atuação estatal, o diálogo tripartite demonstra a força que pode alcançar tal acepção se os principais interessados na questão envidarem esforços para que a noção em estudo possa, de fato, ser verificada no cotidiano trabalhista.

Conversando diretamente com os fins listados pela OIT, José Claudio Monteiro de Brito Filho (2013, p. 49-55) elenca, como direitos mínimos do homem-trabalhador, no plano individual, o direito ao trabalho, a liberdade de escolha do trabalho, a igualdade de oportunidades para e no exercício do trabalho, o direito de exercer o trabalho em condições 
que preservem a saúde do trabalhador, o direito a uma justa remuneração, o direito a justas condições de trabalho, principalmente limitação da jornada de trabalho e existência de períodos de repouso, e a proibição do trabalho infantil; no plano coletivo, a liberdade sindical; e, no plano da seguridade, a proteção contra o desemprego e outros riscos sociais.

$\mathrm{Na}$ visão do autor, são esses direitos que apresentam os limites do que pode ser considerado trabalho decente, entendendo que, sem essa observância, a situação de prestação de serviço estará aquém da ideia de dignidade humana (BRITO FILHO, 2013, p. 55).

Observa-se, portanto, uma aproximação bastante significativa entre os direitos mínimos do trabalhador e os objetivos primordiais da OIT, restando clara a atuação desta na tentativa de proteção do indivíduo, na condição de sujeito prestador de serviço, especialmente levando em consideração a tentativa de romper a alimentação cotidiana dos elevados níveis de desigualdade social.

\subsection{ALGUNS FUNDAMENTOS LEGAIS DO TRABALHO DECENTE E SUA RELEVÂNCIA}

Para Brito Filho (2013, p. 55), em termos de normas internacionais, são considerados preceitos que dão lastro à noção de trabalho decente a Declaração Universal dos Direitos Humanos (1948), o Pacto Internacional dos Direitos Econômicos, Sociais e Culturais (1966), bem como as Convenções da OIT n 29 (sobre o trabalho forçado ou obrigatório - aprovada em 1930), $n^{\circ} 87$ (sobre a liberdade sindical e a proteção do direito sindical - aprovada em 1948), no 98 (sobre o direito de sindicalização e de negociação coletiva - aprovada em 1949), $\mathrm{n}^{\circ} 100$ (sobre a igualdade de remuneração de homens e mulheres trabalhadores por trabalho de igual valor - aprovada em 1951), $\mathrm{n}^{\circ} 105$ (sobre a abolição do trabalho forçado - aprovada em 1957), $\mathrm{n}^{\circ} 111$ (sobre discriminação em matéria de emprego e ocupação - aprovada em 1958), $\mathrm{n}^{\circ} 138$ (sobre idade mínima para admissão - aprovada em 1973) e $\mathrm{n}^{\circ} 182$ (sobre a proibição das piores formas de trabalho infantil e a cão imediata para a sua eliminação aprovada em 1999).

Esse reconhecimento ganha especial importância uma vez observado que "[...] só é possível sustentar ideia global de trabalho decente se entendermos possível a concepção de que existem direitos que devem ser respeitados por todos os Estados, por todos os povos, em todos os lugares" (BRITO FILHO, 2013, p. 29). Trata-se da característica da universalidade 
dos direitos humanos (BONAVIDES, 2015, p. 587), como valores que estabelecem um padrão ético mínimo partilhado pela coletividade mundial.

Mesmo levando em consideração a dificuldade que esse padrão ético mínimo encerra, sobretudo tomando como parâmetro as discussões sobre universalidade dos direitos humanos e relativismo cultural, faz-se salutar pontuar o posicionamento que vem ganhando destaque, na esteira do chamado universalismo de confluência (PIOVESAN, 2012, p. 215-223).

Vale registrar que o Brasil ratificou todas as Convenções consideradas fundamentais (listadas anteriormente), exceto a de $\mathrm{n}^{\mathbf{0}} 87$, de acordo com o site oficial da OIT. Isso ocorre em virtude de algumas escolhas do legislador constituinte, a exemplo da unicidade sindical (permissão de apenas uma organização sindical, patronal ou obreira, em qualquer grau, por base territorial), que compõe o modelo sindical brasileiro, como prevê o art. $8^{\circ}$, II da CF/88.

Para além dos documentos internacionais citados, são marcos legais relacionados ao trabalho decente: 1 . O memorando de entendimento entre a República Federativa do Brasil e a Organização Internacional do Trabalho para o estabelecimento de um programa de cooperação técnica para a promoção de uma agenda de trabalho decente (datado de 2 de junho de 2003); 2. A declaração conjunta do Presidente da República Federativa do Brasil e do Diretor Geral da Organização Internacional do Trabalho (datada de 15 de junho de 2009); e 3. a Portaria $\mathrm{n}^{\mathrm{o}} 114$ do MTE (datada de 27 de fevereiro de 2008 e pontuada no Plano Nacional de Emprego e Trabalho Decente - PNETD -, plano de implementação da Agenda Nacional de Trabalho Decente - ANTD).

Como já mencionado anteriormente, a Constituição Federal de 1988, Lei Maior do país, cita expressamente a dignidade da pessoa humana em seu art. $1^{\circ}$, III, figurando, portanto, na condição de um dos fundamentos da República Federativa do Brasil.

Ingo Wolfgang Sarlet (2015, p. 62) apresenta seu conceito de dignidade da pessoa humana:

[...] a qualidade intrínseca e distintiva de cada ser humano que o faz merecedor do mesmo respeito e consideração por parte do Estado e da comunidade, implicando, nesse sentido, um complexo de direitos e deveres fundamentais que assegurem a pessoa tanto contra todo e qualquer ato de cunho degradante e desumano, como venham a lhe garantir as condições existenciais mínimas para uma vida saudável, além de propiciar e promover sua participação ativa e corresponsável nos destinos da própria existência e da vida em comunidade com os demais seres humanos.

Percebe-se, nesse diapasão, o entendimento que coaduna tudo quanto exposto, reforçando o vislumbre da proposta desenvolvida no presente trabalho, qual seja, do trabalho 
decente como uma forma bastante significativa de materialização da dignidade da pessoa humana.

Outro dispositivo que merece atenção é o art. 149 do Código Penal brasileiro:

Art. 149. Reduzir alguém a condição análoga à de escravo, quer submetendo-o a trabalhos forçados ou a jornada exaustiva, quer sujeitando-o a condições degradantes de trabalho, quer restringindo, por qualquer meio, sua locomoção em razão de dívida contraída com o empregador ou preposto:

Pena - reclusão, de dois a oito anos, e multa, além da pena correspondente à violência.

Em que pese as discussões atuais em virtude do Projeto de Lei no 432 de 2013 (que propõe a retirada, no texto do referido artigo, das expressões jornada exaustiva e condições degradantes de trabalho, gerando, por conseguinte, muita polêmica em virtude disso), tal dispositivo materializa uma proteção relevante para o trabalho, pois registra expressamente situações em que o trabalho decente não é observando, atribuindo à seara penal a oportunidade de auxiliar no combate desse tipo de prática, que contempla um afastamento diametral no que tange à proteção necessária da dignidade da pessoa humana.

Ricardo Maurício Freire Soares (2010, p. 142) entende a dignidade da pessoa humana como mecanismo de vedação da degradação do ser humano, tendo em vista a proteção da integridade física e moral dos indivíduos.

Como afirma José Cláudio Monteiro de Brito Filho (2013, p. 42), “dar trabalho, e em condições decentes, então, é forma de proporcionar ao homem os direitos que decorrem desse atributo que lhe é próprio: a dignidade".

De maneira clara, Beatriz Cardoso Montanhanha (2014, p. 89) assevera: “o sistema jurídico brasileiro estrutura-se sobre a natural indissolubilidade do trabalho e do homem, de sorte que disciplinar a relação de emprego é regular a atuação do capital não somente sobre a atividade laboral, mas sobre o próprio homem".

Observa-se, nessa senda, a relevância da esfera laboral na vida humana, estabelecendo íntima ligação com a dignidade em uma de suas múltiplas possibilidades de reflexo e base para o indivíduo.

Flávia Piovesan (2012, p. 83), após citar os objetivos fundamentais do Estado brasileiro, previstos no art. $3^{\circ}$ da $\mathrm{C} / 88$, afiança: "infere-se desses dispositivos quão acentuada é a preocupação da Constituição em assegurar os valores da dignidade e do bem-estar da pessoa humana, como imperativo de justiça social".

Como vem sendo desenvolvido nesse texto, o trabalho digno reverbera na vida humana de maneira absolutamente direta, garantindo bem estar e auxiliando na promoção da 
justiça social, fatores que a autora indica e que, no mundo fático, são bastante perceptíveis em se tratando de análise juslaboralista.

Examinando o princípio da dignidade humana, manifesta-se Thiago Luís Santos Sombra (2011, p. 43-44):

[...] a elevação do princípio da dignidade da pessoa humana à condição de fundamento do Estado brasileiro tem o condão de fazer com que essa mesma ordem jurídico-política fique obrigada a conferir primazia a esse preceito e aos direitos fundamentais nele consubstanciados, seja nas relações com o Estado, seja nas relações entre particulares.

As relações de emprego podem, portanto, ser inseridas nesse contexto, haja vista a possibilidade de cobrança da efetivação dos direitos sociais também na relação entre particulares - que, geralmente, é a seara de atuação do Direito do Trabalho.

Para concluir unindo as duas perspectivas propostas nesse tópico e utilizando o fundamento comum a todo o processo, Flávia Piovesan (2012, p. 86) demonstra a relevância do princípio da dignidade humana em sede nacional e internacional:

Sustenta-se que é no princípio da dignidade humana que a ordem jurídica encontra o próprio sentido, sendo seu ponto de partida e seu ponto de chegada, para a hermenêutica constitucional contemporânea. Consagra-se, assim, a dignidade humana como verdadeiro superprincípio, a orientar tanto o Direito Internacional como o Direito interno.

Essa visão para além do cenário brasileiro reforça de maneira ainda mais vigorosa a ilação com o tema em estudo, em virtude de seu tratamento internacional (objetivo, inclusive, do início do texto do presente item). Reforça-se, assim, que compreender e aplicar a noção de trabalho decente ultrapassa a proposta de um objetivo pátrio, devendo existir a percepção do entendimento de que essa necessidade é imperiosa em todo e qualquer lugar, tendo em vista a própria condição humana do trabalhador.

\section{CONSIDERAÇÕES FINAIS}

Cumprindo o fito proposto, restou evidenciada a relevância de analisar detalhadamente o conceito de trabalho decente proposto pela OIT, tendo em vista a profundidade e dimensão que as palavras chave desse enunciado proporcionam para o entendimento da noção em estudo, sendo estas trabalho adequadamente remunerado, liberdade, equidade, segurança e vida digna. 
Quanto à terminologia utilizada no Brasil, trabalho decente é uma tradução literal da expressão decent work, destoando da nomenclatura adotada no italiano e, especialmente, da escolha feita por Portugal, que preferiram seguir a linha de dignidade (trabalho digno). Pelo estudo realizado do conceito, percebe-se a grande afinidade do significado minudenciado com o significante tendendo para a abordagem do labor digno.

O diálogo dos objetivos da OIT com a noção de trabalho decente é patente, sendo passível de afirmação a identidade que a definição possui com a própria essência e a razão de ser da OIT.

Por fim, consiste em substrato bastante significativo o arcabouço legal existente no mundo jurídico passível de ser vinculado à ideia de trabalho decente, tanto no plano internacional quanto em âmbito nacional. A observância em sede de internacionalidade é deveras importante, com o condão de fortalecer um padrão ético mínimo a ser respeitado em todo o planeta. Não se deve olvidar, contudo, o quão benéfico é o pensamento voltado para o cenário das normas internas, uma vez que representam não só o reconhecimento do Brasil a respeito de tema tão relevante, mas também reforçam, de maneira inconteste, o imperativo de observância em território nacional dessa aplicação indispensável à concretização da dignidade da pessoa humana em sua plenitude.

Dessa forma, verifica-se que conhecer os aspectos conceitual, terminológico e legal da noção de trabalho decente emprega significado ainda mais alicerçado para tal expressão, gerando maior base para sua aplicação e, consequentemente, fortalecendo os caminhos de sua execução, tão cogente na edificação de uma sociedade mais justa e igualitária como se anseia.

\section{REFERÊNCIAS}

AUBERT, Francis. A tradução literal: impossibilidade, inadequação ou meta? Ilha do Desterro, A Journal of English Language, Literatures in English and Cultural Studies, Florianópolis, n. 25/26, p. 185-192, jan. 1991. ISSN 2175-8026. Disponível em: <https://periodicos.ufsc.br/index.php/desterro/article/view/8782/8144>. Acesso em: 22 set. 2016.

BARBOSA, Heloísa Gonçalves. Procedimentos técnicos da tradução: uma nova proposta. 3. ed. Campinas: Pontes, 2007.

BONAVIDES, Paulo. Curso de Direito Constitucional. 30. ed. São Paulo: Malheiros, 2015. 
BRASIL. Constituição da República Federativa do Brasil. 1988. Disponível em: <http://www.planalto.gov.br/ccivil_03/constituicao/constituicaocompilado.htm>. Acesso em: 09 ago. 2016.

BRASIL. Decreto Lei no 2.848 de 07 de dezembro de 1940. Código Penal. Disponível em: <http://www.planalto.gov.br/ccivil_03/decreto-lei/Del2848.htm>. Acesso em: 02 set. 2016.

BRITO FILHO, José Claudio Monteiro. Trabalho decente: análise jurídica da exploração do trabalho - trabalho escravo e outras formas de trabalho indigno. 3. ed. São Paulo: LTr, 2013.

CONFEDERAÇÕES DE EMPREGADORES. Emprego e trabalho decente: um conceito produtivo para o país. Brasília, 2011, p. 11, 13-15. Disponível em:

$<$ http://www.cnc.org.br/central-do-conhecimento/livros/emprego-e-trabalho-decente-umconceito-produtivo-para-o-pais>. Acesso em: 19 set. 2016.

DECENTE. In: DICIONÁRIO da Língua Portuguesa. Lisboa: Priberam Informática, 2013. Disponível em: <http://www.priberam.pt/DLPO/decente>. Acesso em: 20 jul. 2016.

DECENTE. In: DICIONÁRIO Michaelis. São Paulo: Melhoramentos, 2009. Disponível em: $<$ http://michaelis.uol.com.br/moderno/portugues/index.php?lingua=portuguesportugues\&palavra=decente>. Acesso em: 20 jul. 2016.

FILME. Papeando com Pamplona. Sebastião Geraldo de Oliveira. Saúde e segurança no trabalho. 2016. Disponível em: < https://www.youtube.com/watch?v=g6li9-

Cw8tI\&list=PLdUugIhWdpiak2_tX-Nne2hiIPmhujXx\&index=25>. Acesso em: 17 set. 2016.

GEERTZ, Clifford. A interpretação das culturas. Rio de Janeiro: LTC, 2012.

INTERNATIONAL LABOR ORGANIZATION. Decent work agenda. Disponível em: <http://www.ilo.org/global/about-the-ilo/lang--en/index.htm>. Acesso em: 16 set. 2016.

LIMA, Firmino Alves. Teoria da discriminação nas relações de trabalho. Rio de Janeiro: Elsevier, 2011.

MACHADO, Sidney. $O$ direito à proteção ao meio ambiente de trabalho no Brasil: os desafios para a construção de uma racionalidade normativa. São Paulo: LTr, 2001.

MATEUS, Maria Helena Mira. Se a língua é um factor de identificação cultural, como se compreende que a mesma língua identifique culturas diferentes? CARDOSO, Suzana Alice Marcelino; MOTA, Jacyra Andrade; SILVA, Rosa Virgínia Mattos e (org.). Quinhentos anos de história linguística do Brasil. Salvador: Secretaria da Cultura e Turismo do Estado da Bahia, 2006. p. 63- 80.

MARTINEZ, Luciano. Curso de Direito do Trabalho. 7. ed. São Paulo: Saraiva, 2016.

MARX, Karl; ENGELS, Friedrich. O Capital: livro 1 - o processo de produção do capital. 33. ed. Rio de Janeiro: Civilização Brasileira, 2014. 
MONTANHANHA, Beatriz Cardoso. A dinâmica do poder nas relações de trabalho e os impactos sobre a dignidade humana. São Paulo: LTr, 2014.

NASCIMENTO, Amauri Mascaro. Salário: conceito e proteção. São Paulo: LTr, 2008.

NASCIMENTO, Amauri Mascaro. Teoria jurídica do salário. 2. ed. São Paulo: LTr, 1997.

OLVERA, Óscar Rodriguez. Teoria de los derechos sociales em la constitución abierta. Granada: Comares, 1998.

ORGANIZAÇÃO INTERNACIONAL DO TRABALHO. A OIT no Brasil: trabalho decente para uma vida digna. Brasília, 2012, p. 6. Disponível em:

<http://www.oitbrasil.org.br/sites/default/files/topic/gender/pub/oit\%20no\%20brasil_folder_8 09.pdf>. Acesso em: 20 ago. 2016.

ORGANIZAÇÃO INTERNACIONAL DO TRABALHO. Convenções não ratificadas. Disponível em: < http://www.oitbrasil.org.br/content/convention_no>. Acesso em: 25 ago. 2016.

ORGANIZAÇÃO INTERNACIONAL DO TRABALHO. Governo do Brasil avança na implementação da Agenda do Trabalho Decente. Brasília, 2010a. Disponível em: $<$ http://www.oit.org.br/content/governo-do-brasil-avan\%C3\%A7a-naimplementa\%C3\%A7\%C3\%A3o-da-agenda-do-trabalho-decente>. Acesso em: 20 ago. 2016.

ORGANIZAÇÃO INTERNACIONAL DO TRABALHO. Promovendo o trabalho decente: apresentação. [ca. 2010]. Disponível em:

<http://www.oitbrasil.org.br/content/apresenta\%C3\%A7\%C3\%A3o>. Acesso em: 20 ago. 2016.

ORGANIZAÇÃO INTERNACIONAL DO TRABALHO. Trabalho digno - a chave do progresso social. Lisboa, 2010b. Disponível em:

<http://www.ilo.org/public/portugue/region/eurpro/lisbon/html/portugal_visita_guiada_02_pt. htm>. Acesso em: 16 set. 2016.

ORGANIZACIÓN INTERNACIONAL DEL TRABAJO. Trabajo decente. Disponível em: <http://www.ilo.org/global/topics/decent-work/lang--es/index.htm>. Acesso: 16 set. 2016.

ORGANISATION INTERNATIONALE DU TRAVAIL. Travail décent. Disponível em: <http://www.ilo.org/global/topics/decent-work/lang--fr/index.htm>. Acesso em: 16 set. 2016.

ORGANIZZAZIONE INTERNAZIONALE DEL LAVORO. Lavoro dignitoso per tutti: gli obiettivi principali dell'ILO. Disponível em: <http://www.ilo.org/rome/ilo-cosa-fa/lavorodignitoso/lang--it/index.htm>. Acesso em: 16 set. 2016.

PESSANHA, Vanessa Vieira. O dever fundamental do empregador de qualificar seus empregados. 2015. 200 f. Tese (Doutorado) - Faculdade de Direito, Universidade Federal da Bahia, Salvador, 2015. 
PIOVESAN, Flávia. Direitos Humanos e o Direito Constitucional Internacional. 13. ed. São Paulo: Saraiva, 2012.

RIVERO, Jean; MOUTOUH, Hugues. Liberdades públicas. Trad. Maria Ermanita de Almeida Prado Galvão. São Paulo: Martins Fontes, 2006.

SARLET, Ingo Wolfgang. Dignidade da pessoa humana e direitos fundamentais na Constituição Federal de 1988. 10. ed. Porto Alegre: Livraria do Advogado, 2015.

SILVA, Rosa Virgínia Mattos e. O português são dois: novas fronteiras, velhos problemas. São Paulo: Parábola, 2004.

SILVA NETO, Manoel Jorge e. Proteção constitucional ao trabalho da prostituta. DANTAS, Miguel Calmon; CUNHA JÚNIOR, Dirley da (org.). Desafios do constitucionalismo brasileiro. Salvador: Juspodvim, 2009, v. 1, p. 99-119.

SILVA NETO, Manoel Jorge e. Trabalho forçado. In: PINTO, José Augusto Rodrigues; MARTINEZ, Luciano; MANNRICH, Nelson (org.). Dicionário Brasileiro de Direito do Trabalho. São Paulo: LTr, 2013.

SOARES, Ricardo Maurício Freire. O princípio constitucional da dignidade da pessoa humana. São Paulo: Saraiva, 2010.

SOMBRA, Thiago Luís Santos. A eficácia dos direitos fundamentais nas relações privadas. 2. ed. São Paulo: Atlas, 2011.

SÜSSEKIND, Arnaldo; MARANHÃO, Délio; VIANNA, Segadas; TEIXEIRA, Lima. Instituições de Direito do Trabalho. 22. ed. São Paulo: LTr, 2005. 